\title{
Endoplasmic Reticulum Stress Induces HRD1 to Protect Alveolar Type II Epithelial Cells from Apoptosis Induced by Cigarette Smoke Extract
}

\author{
Shuang-xiang Tan ${ }^{a, b}$ Di-xuan Jiang ${ }^{a}$ Rui-cheng Hua,b Ai-guo Daia \\ Gui- xiang Gan ${ }^{\mathrm{a}}$ Dai-yan Fu ${ }^{\mathrm{a}}$ Chun-chu Kong ${ }^{\mathrm{a}}$ Yun-rong Chen ${ }^{\mathrm{a}} \quad$ Li-Le Wang $^{\mathrm{a}}$ \\ Jie Lia
}

aDepartment of Respiratory Medicine, Hunan Provincial People's Hospital/The first affiliated hospital of Hunan Normal University, Changsha, China, 'bunan Province Institute of Gerontology, Hunan Provincial People's Hospital/The first affiliated hospital of Hunan Normal University, Changsha, China

\section{Key Words}

Cigarette smoke extract • Hrd1 • ER stress • Alveolar type II epithelial cells $\bullet$ CHOP

\begin{abstract}
Background/Aims: Cigarette smoking is a major risk factor of chronic obstructive pulmonary disease. This study aimed to examine the effects of cigarette smoke extract (CSE) on alveolar type II epithelial cells (AECII) and investigate the underlying mechanism. Methods: Primary AECII were isolated from rat lung tissues and exposed to CSE. Apoptosis was detected by flow cytometry. Protein expression was detected by Western blot analysis. Results: Primary rat AECII maintained morphological and physiological characteristic after 3 passages. CSE increased the expression of ER specific pro-apoptosis factors $\mathrm{CHOP}$ and caspase 12, and the phosphorylation of JNK in AECII. CSE activated ER stress signaling and increased the phosphorylation of PERK, eIF2 $\alpha$ and IRE1. Furthermore, CSE induced the expression of Hrd1, a key factor of ER-associated degradation, in AECII. Knockdown of Hrd1 led to more than 2 fold increase of apoptosis, while overexpression of Hrd1 attenuated CSE induced apoptosis of AECII. Conclusions: Our results suggest that ER stress induces HRD1 to protect alveolar type II epithelial cells from apoptosis induced by CSE.
\end{abstract}

(C) 2017 The Author(s)

Published by S. Karger AG, Basel

\section{Introduction}

Chronic obstructive pulmonary disease (COPD) is a disease of progressive and irreversible airflow limitation. The incidence and mortality rate of COPD keep increasing yearly, with significant impact on the health of people worldwide. Although the pathogenesis of COPD

S. Tan and D. Jiang contributed equally to this work.

Rui-cheng $\mathrm{Hu}$,

KARGER 
is still not fully understood, a variety of studies have shown that inflammation, oxidative stress, protease/anti-protease imbalance, and apoptosis of lung cells are involved in COPD [1-3]. Cigarette smoking is the most important risk factor of COPD. Abnormal inflammatory response to cigarette smoke in the lung promotes COPD development [4]. Alveolar type II epithelial cells (AECII) play important role in the maintenance of normal lung structure and help the repair and recovery of the lung after biological and physical lung damages [5, 6]. Cigarette smoking has been shown to cause the apoptosis of AECII [7].

Endoplasmic reticulum (ER) is an important organelle in eukaryote cells that regulates protein synthesis, modification and secretion as well as $\mathrm{Ca}^{2+}$ concentration. Under certain conditions such as the lack of energy, redox imbalance, glycosylation malfunction and the exposure to toxic materials, modification and folding of newly synthesized polypeptides would be affected, and unfolded or misfolded proteins would accumulate in ER, causing ER stress and unfolded protein response (UPR). UPR could activate downstream signaling pathways PERK, eIF2 $\alpha$ and IRE1 to temperately repress protein synthesis, enhance protein folding capacity in ER and facilitate the degradation of unfolded protein to recover ER function. While ER stress may promote cells to adapt to extrinsic stimuli, persistent or strong ER stress often leads to cell apoptosis [8-12]. As a common air contaminant, cigarette smoke induces ER stress in lung cells.

During ER stress, incorrectly folded protein will be degraded through ER-associated degradation (ERAD) [13]. ERAD includes three steps, substrate recognition, substrate ubiquitination and reverse transport, and substrate degradation. In some situations, such as when significant amount misfolded proteins exist, only the degradation of these proteins through ERAD could avoid the accumulation of large amount of misfolded proteins in ER and protect the cells from ER stress induced apoptosis. Hrd1 is a specific ubiquitin E3 ligase on ER membrane. Hrd1 expression is increased during ER stress and it is a key protein in ERAD. By the formation of different ubiquitin ligase complex, Hrd1 participates in the ubiquitination of multiple types of ERAD substrates to promote the degradation of misfolded proteins through ERAD and protect the cells from ER stress induced damage [14].

In this study, we established an in vitro system to investigate the effects of cigarette smoke on ER stress and ER stress induced apoptosis in primary ACEII cells. Our results showed that cigarette smoke induced apoptosis in ACEII cells via the activation of JNK, CHOP and caspase 12. By manipulating Hrd1 expression level in ACEII cells, we found that Hrd1 protected ACEII cells from cigarette smoke induced apoptosis.

\section{Materials and Methods}

Preparation of cigarette smoke extract

The cigarette (Brand: Furong) was purchased from Hunan Changde Tobacco Ltd (Hunan, China). Cigarette smoke extract (CSE) was prepared as described below. Briefly, $35 \mathrm{~mL}$ cigarette smoke was collected using syringe and injected into a flask with $5 \mathrm{~mL}$ PBS via triple connector in 2s for 10 times, the flask was swirled for $1 \mathrm{~min}$ between each injection to thoroughly dissolve cigarette smoke in PBS. Then solution was adjusted to $\mathrm{pH} 7.4$ using $1 \mathrm{~mol} / \mathrm{L} \mathrm{NaOH}$, and sterilized by passing through $0.22 \mu \mathrm{m}$ filter. The resulting solution was considered as $100 \%$ CSE. 2.5\%, 5\%, 10\% CSE were prepared by dilution in serum free culture medium.

\section{Animals}

Healthy SD male rats (weight 180-220 g) were purchased from Experimental Animal Center of Central South University (Permit No. SCXK 2006-0002) (Changsha, China). All animal experiments were reviewed and approved by Medical Ethics Committee of Hunan provincial People's Hospital.

Isolation and culture of ACE II

SD rats were first anesthetized with chloral hydrate at the dose of $3 \mathrm{~mL} / \mathrm{kg}$, then topically sterilized by using $70 \%$ ethanol and put into biosafety cabinet. The rats were cut open along the center line to expose 


\section{Cellular Physiology Cell Physiol Biochem 2017;43:1337-1345 \\ \begin{tabular}{ll|l} 
DOI: 10.1159/000481845 & $\begin{array}{l}\text { O 2017 The Author(s). Published by S. Karger AG, Basel } \\
\text { www.karger.com/cpb }\end{array}$ \\
and Biochemistry Published online: October 09, 201
\end{tabular}}

Tan et al.: HRD1 Protects AECII from Apoptosis

the chest. The lungs were first perfused with 1x PBS via main lung arterial till the color turned to white and continued to perfuse with $50 \mathrm{~mL}$ HBSS. Then the whole heart and lungs were dissected with trachea and transferred to a sterile flask. The lungs were perfused via trachea with PBS and HBSS each for 10 times. Next, the lungs were injected with digestion solution containing $0.5 \mathrm{mM}$ EDTA, $0.5 \mathrm{mM} \mathrm{EGTA}, 0.08 \%$ trypsin and $1 \mathrm{~g} / \mathrm{L}$ collagenase I (Solarbio, Beijing, China) till they were fully extended, the solution was removed after $1 \mathrm{~min}$ and the lungs were re-injected with fresh digestion solution till they were fully extended, and incubated in $30^{\circ} \mathrm{C}$ water bath for $20 \mathrm{~min}$. Digested lung tissues were cut into $1 \mathrm{~mm}^{3}$ pierces and shaken for $10 \mathrm{~min}$ in a shaker. The suspension was passed sequentially through 100 mesh, 300 mesh and 500 mesh stainless steel filters, and then centrifuged at $1,000 \mathrm{rpm}$ for $10 \mathrm{~min}$ at $4^{\circ} \mathrm{C}$. The collected cells were resuspended in DMEM/F12 medium at $2 \times 10^{6} / \mathrm{mL} .10 \mathrm{~mL}$ cell suspension was seeded on each $100 \mathrm{~mm}$ cell culture plate and incubated in $5 \% \mathrm{CO}_{2}$ incubator at $37^{\circ} \mathrm{C}$ for $1 \mathrm{~h}$, then the unattached cells were transferred to rat IgG (Solarbio) coated plates and incubated in $5 \% \mathrm{CO}_{2}$ incubator at $37^{\circ} \mathrm{C}$. After $1 \mathrm{~h}$, the plate was gently rocked, and the medium was transferred into centrifuge tube and centrifuged at $800 \mathrm{rpm}$ for $10 \mathrm{~min}$. The collected cells were re-suspended in complete DMEM/F12 medium and seeded in Matrigel coated plates or slides for culture in $5 \% \mathrm{CO}_{2}$ incubator at $37^{\circ} \mathrm{C}$. The cells were passaged at $1: 2$ ratio after $72 \mathrm{~h}$ of culture.

\section{Electron microscopy}

ACE II cells were collected after incubation with $0.25 \%$ trypsin, washed with $1 \mathrm{x}$ PBS twice, then fixed in $2.5 \%$ glutaraldehyde at $4^{\circ} \mathrm{C}$ for $2 \mathrm{~h}$, followed by fixing in $1 \% \mathrm{H}_{2} \mathrm{OsO}_{6}$ at $4^{\circ} \mathrm{C}$ for $1 \mathrm{~h}$. Cells were dehydrated using acetone, embedded in epoxy resin and sectioned. After staining, cells were observed under transmission electron microscope at Central South University.

\section{Immunohistochemistry}

ACE II cells were cultured on Matrigel coated cover slides placed in 6-well plates for 24 or $48 \mathrm{~h}$. After rinsing with PBS 3 times, the cover slides were fixed with ice cold methanol for $20 \mathrm{~min}$, then incubated with $0.1 \%$ Triton X-100 for $30 \mathrm{~min}$ and $3 \% \mathrm{H} 2 \mathrm{O} 2$ for $30 \mathrm{~min}$. Slides were blocked with goat serum at $37^{\circ} \mathrm{C}$ for 30 min and incubated with rabbit anti-SP-A antibody (Boster, Wuhan, China) at 1:400 dilution overnight at $4^{\circ} \mathrm{C}$. The slides were washed with PBS twice and incubated with goat anti-rabbit secondary antibody for $30 \mathrm{~min}$. Finally, the slides were washed with PBS twice and stained with DAB and counterstained with hematoxylin. The slides were observed under light microscope. For negative control PBS was used instead of primary antibody.

\section{Alkaline phosphatase staining}

ACE II cells cultured on Matrigel coated cover slides were stained with BCIP/NBT staining kit (Solarbio). The slides were washed with PBS 3 times, then fixed with 4\% paraformaldehyde for $15 \mathrm{~min}$. Fresh working solution was prepared by mixing $40 \mu \mathrm{L} 25 \mathrm{x}$ nitro blue tetrazolium (NBT) with $1 \mathrm{~mL}$ reaction buffer, followed by the addition of $40 \mu \mathrm{L} 25 \times 5$-bromo-4-chloro-3-indolyl phosphate (BCIP). The slides were incubated with working solution at room temperature for $30 \mathrm{~min}$, then washed with ddH2O once, stained with nuclear fast red, followed by dehydration and sealed with mounting medium. The slides were observed under light microscope.

\section{Short hairpin RNA (shRNA) constructs}

The sequences targeting rat Hrd1 CGCATTGTCTCTCTTATGT and negative control sequence TTCTCCGAACGTGTCACGT were synthesized and inserted into lentivirus-packaging shRNA expression vector (purchased from GenePharma, Shanghai, China). The recombinant vectors were mixed with lentiviral packaging system and co-transfected into HEK293 cells using DNA Transfection Reagent. The released lentiviral particles were titrated by FACS analysis of infected HEK293 cells. ACEII cells were seeded onto 6-well plates at $1 \times 10^{5}$ cells per well. After the cells grew to $30-50 \%$ confluence, the cells were washed with HBSS twice and incubated with $20 \mu \mathrm{L} 1 \times 10^{8} \mathrm{TU} / \mathrm{mL}$ lentiviral particles in $1 \mathrm{~mL}$ fresh medium at $37^{\circ} \mathrm{C}$ in a $5 \% \mathrm{CO} 2$ incubator for $24 \mathrm{~h}$. Then fresh medium was changed and the cells were cultured for 4 more days.

Real-time PCR

Total RNA was prepared from ACE II cells using Trizol (Invitrogen) following the manufacturer's manual. cDNA was synthesized from $5 \mu \mathrm{g}$ total RNA using M-Mulv reverse transcriptase $(2,000 \mathrm{U})$ 


\section{Cellular Physiology Cell Physiol Biochem 2017;43:1337-1345 \begin{tabular}{l|l|l} 
DOI: 10.1159/000481845 & $\begin{array}{l}\text { O 2017 The Author(s). Published by S. Karger AG, Basel } \\
\text { www.karger.com/cpb }\end{array}$ \\
\hline
\end{tabular} \\ Tan et al.: HRD1 Protects AECII from Apoptosis}

with $1 \mu \mathrm{L} 0.2 \mu \mathrm{g} / \mu \mathrm{L}$ random hexamer primer and $10 \mathrm{mM}$ dNTPs and stored at $-20^{\circ} \mathrm{C}$. Real-time PCR was performed in $20 \mu \mathrm{L}$ reaction mixture with $2 \mu \mathrm{L}$ cDNA template at the following parameters: 1 cycle $95^{\circ} \mathrm{C}, 3 \mathrm{~min} ; 40$ cycles $95^{\circ} \mathrm{C}, 12 \mathrm{~min}, 62^{\circ} \mathrm{C} 40 \mathrm{sec}$. Primers were as follows: rat Hrd1, forward primer, $5^{\prime}$ CACGGAGCTGTTTACAGGCTTTATC 3', reverse primer, 5' TAATGGCAAAGAGGCGGAAATGTG 3'; rat $\beta$-actin, forward primer, 5' CGTAAAGACCTCTATGCCAACA 3', reverse primer, 5' GGAGGAGCAATGATCTTGATCT 3'.

\section{Western blot analysis}

Cells were collected and lysed in $200 \mu \mathrm{L}$ ice cold lysis buffer with freshly added PMSF and phosphatase inhibitors cocktail. The lysates were centrifuged at $12,000 \mathrm{rpm}$ for $20 \mathrm{~min}$ at $4^{\circ} \mathrm{C}$, and the supernatants were collected. The protein concentration of the lysates was determined using BCA kit (Beyotime Biotechnology, Shanghai, China) following the manufacturer's protocol. $50 \mu \mathrm{g}$ samples were separated by SDS-PAGE electrophoresis and transferred to PVDF membranes. The membranes were blocked with 5\% non-fat milk for $1 \mathrm{~h}$, and then probed with primary antibody overnight at $4^{\circ} \mathrm{C}$. Rabbit anti-PERK, anti-p-PERK, anti-eIF2 $\alpha$, anti-p-eIF2 $\alpha$, anti-CHOP antibodies and mouse anti-JNK antibody were from Santa Cruz (Dallas, TX, USA). Rabbit anti-p-JNK antibody was from Cell Signaling. Rabbit anti-IRE, anti-p-IRE, anti-caspase 12, and antiGAPDH antibodies were from Abcam (Cambridge, MA, USA). Rabbit anti-Hrd1 antibody was from Proteintech (Rosemont, IL, USA). The membranes were washed with TBST 3 times, and then probed with horseradish peroxidase conjugated anti-rabbit or anti-mouse secondary antibody for $1 \mathrm{~h}$ at room temperature. Bands were then visualized by using enhanced chemiluminescence (ECL) (PerkinElmer, USA) detection system.

Flow cytometry analysis of apoptosis

Cells were cultured on 6-well plate to 70\% confluence, and then treated with $0 \%, 2.5 \%$, 5\%, and $10 \%$ $\mathrm{CSE}$ in $5 \% \mathrm{CO} 2$ incubator at $37^{\circ} \mathrm{C}$ for $12 \mathrm{~h}$. After the treatment, cells were cultured in fresh medium for $48 \mathrm{~h}$, then collected, washed and resuspended in $400 \mu \mathrm{L}$ Binding Buffer. The cells were stained with $5 \mu \mathrm{L}$ Annexin V-FITC and $5 \mu \mathrm{L}$ Propidium Iodide (Apoptosis Detection Kit, Jiamay Biotech, Beijing, China) for $10 \mathrm{~min}$ at room temperature and then immediately subjected to flow cytometry on a flow cytometer and the data were analyzed with the BD FACS Diva software.

\section{Statistical analysis}

Data were analyzed using the SPSS version 13.0 statistical analysis package (SPSS Inc., Chicago, IL, USA). In each test, the data were expressed as the mean \pm SD and analyzed by t-test or ANOVA if appropriate. $\mathrm{P}<0.05$ was accepted as statistically significant difference.

\section{Results}

CSE induces apoptosis in rat type II aleolar epithelial cells

To examine the effect of CSE on alveolar type II epithelial cells (AECII), an in vitro system was established by isolating primary AECII cells from rat lung tissues. Morphological and immunohistological analysis confirmed that AECII after 3 passages possessed the typical AEC II characteristics as original AECII (Fig. 1A). Both original and 3rd passage cells showed typical AECII morphology under electron microscopy, such as lots of micropillar on the cell surface and lots of concentric or parallel osmiophilic multilamellar body in the cytosol (Fig. 1A). More than 95\% cells in both original and 3rd passage cells were stained positively for SP-A and AKP (Fig. 1A). These data demonstrated that the 3rd passage and original primary AECII possessed AECII characteristics and could serve as experimental model of AECII in vitro.

Next AECII cells were treated with CSE at different concentrations for $12 \mathrm{~h}$ and apoptotic cells were detected using flow cytometry. CSE significantly induced apoptosis in AECII in a dose dependent manner. 2.5\% CSE did not increase apoptosis rate, while $5 \%$ and $10 \%$ of CSE increased apoptosis rate by 2.5 and 6.1 fold, respectively (Fig. 1B). These results suggest that CSE is toxic to AECII and could induce apoptosis in AECII. 


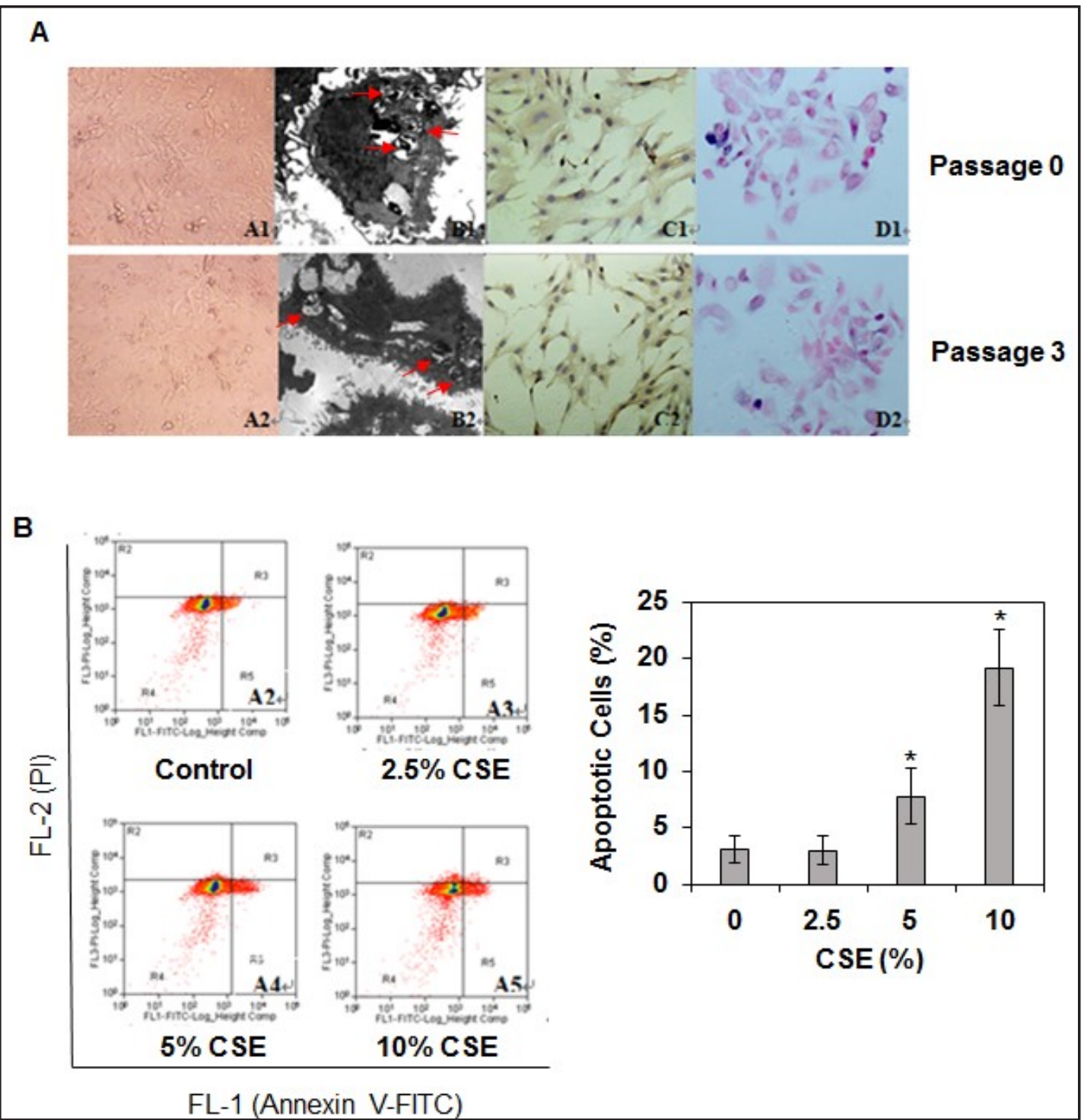

Fig. 1. CSE induces apoptosis of AECII. A. The 3rd passage ACEII maintained similar morphology and biological characteristics as original ACEII. A1 \& A2, Morphology of AECII under light inverted microscope (100 $\mathrm{x}$; $\mathrm{B} 1$ \& B2, Typical features of AECII under transmission electron microscope $(10,000 \mathrm{x})$. The multilamellar body was marked with red arrows; C1 \& C2, SP-A immunocytochemistry of ACEII; D1 \& D2, Alkali kinase phosphatase activity in AECII. B. CSE induced apoptosis in rat ACEII. Rat ACEII were treated with indicated dose of CSE for $12 \mathrm{~h}$, apoptotic cells were analyzed using flow cytometry after Anexin-FITC and PI staining. $* \mathrm{P}<0.05$ vs. $\mathrm{CSE}$ at $0 \%$.

\section{CSE induces ER stress in AEC II}

It is reported that CSE affects mitochondrial morphology and function [15]. To investigate whether CSE affects ER function, we investigated the markers of ER stress response such as PERK, IRE $1 \alpha$ and eIF $2 \alpha$. We found that the phosphorylation of PERK, eIF2 $\alpha$ and IRE1 $\alpha$ increased after treatment with CSE for different periods (Fig. 2A). These results suggest that CSE induces ER stress response.

Activation of IRE1 $\alpha$ during ER stress could activate JNK and p38 to induce apoptosis. As shown in Fig. 2B, while total JNK level remained unchanged, the phosphorylation of JNK significantly increased after CSE treatment. In addition, the expression of ER specific caspase 12 significantly increased after CSE treatment up to $12 \mathrm{~h}$. Taken together, these results in-

\section{KARGER}


Fig. 2. ER stress mediates CSE induced apoptosis of AECII. A. Western blot analysis of the phosphorylation of PERK, eIF $2 \alpha$ and IRE1 in AECII treated with $10 \%$ CSE for indicated time. B. Western blot analysis of the phosphorylation of JNK and caspase 12 expression in AECII treated with 10\% CSE for indicated time. GAPDH was loading control.

dicate that CSE could activate ER stress induced apoptosis through the activation of JNK and caspase 12 .

Hrd1 is induced by CSE and protects ACE II from CSE induced apoptosis

ER is a major organelle for protein process-

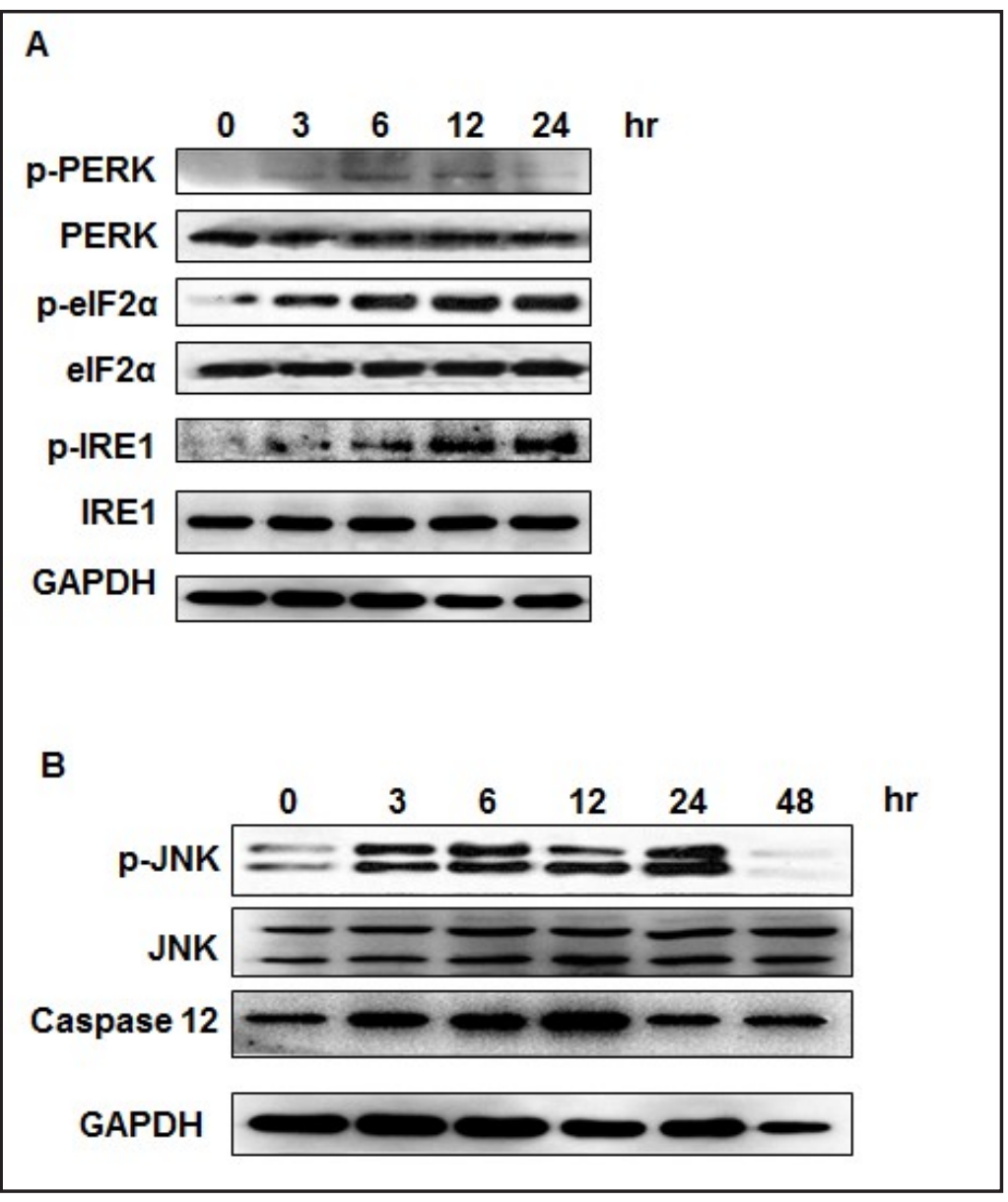
ing, and the perturbation or malfunction of ER often leads to the accumulation of unfolded protein [16]. An ubiquitin mediated ER-associated degradation (ERAD) system is responsible to remove unfolded proteins to alleviate stress $[17,18]$. Hrd1 is a substrate specific E3 ligase that can label unfolded protein and target them for proteasome degradation $[19,20]$. To understand whether cells can alleviate deleterious effects of CSE via the activation of ERAD, we investigated the regulation of Hrd1. RT-PCR analysis showed that Hrd1 mRNA level increased at $3 \mathrm{~h}$ after CSE treatment, peaked at $12 \mathrm{~h}$ with more than 6 fold increase and started to decline at $24 \mathrm{~h}$ after CSE treatment (Fig. 3A). Furthermore, Western blot analysis showed that Hrd1 protein level increased about 2 fold at $12 \mathrm{~h}$ and kept increasing to 3.8 fold at $48 \mathrm{~h}$ after CSE treatment (Fig. 3B). These results demonstrate that Hrd1 expression is upregulated after CSE treatment in ACE II.

To further investigate possible protective role of Hrd1 in AEC II after CSE treatment, we established lentivirus mediated shRNA system to knockdown Hrd1 expression in ACE II cells (Fig. 3C). As a control, we overexpressed Hrd1 in AEC II cells using Hrd1 expression vector (Fig. 3D). As expected, knockdown of Hrd1 significantly increased apoptosis in AEC II after CSE treatment, while overexpression of Hrd1 decreased apoptosis in AEC II, especially in cells treated with CSE for 24 and 48 h (Fig. 3E). These results demonstrate that Hrd1 protects ACE II from CSE induced apoptosis.

Pro-apoptotic transcription factor CHOP is a key mediator of ER stress induced apoptosis [21]. CHOP level was induced by CSE treatment in ACE II as expected (Fig. 3F). Knockdown of Hrd1 in ACE II led to further induction of CHOP, with more than two fold increase of CHOP at $6 \mathrm{~h}$ after treatment compared with control ACE II (Fig. 3F). In contrast, overexpression of Hrd1 in ACE II attenuated CHOP induction after CSE treatment, although the difference was

\section{KARGER}




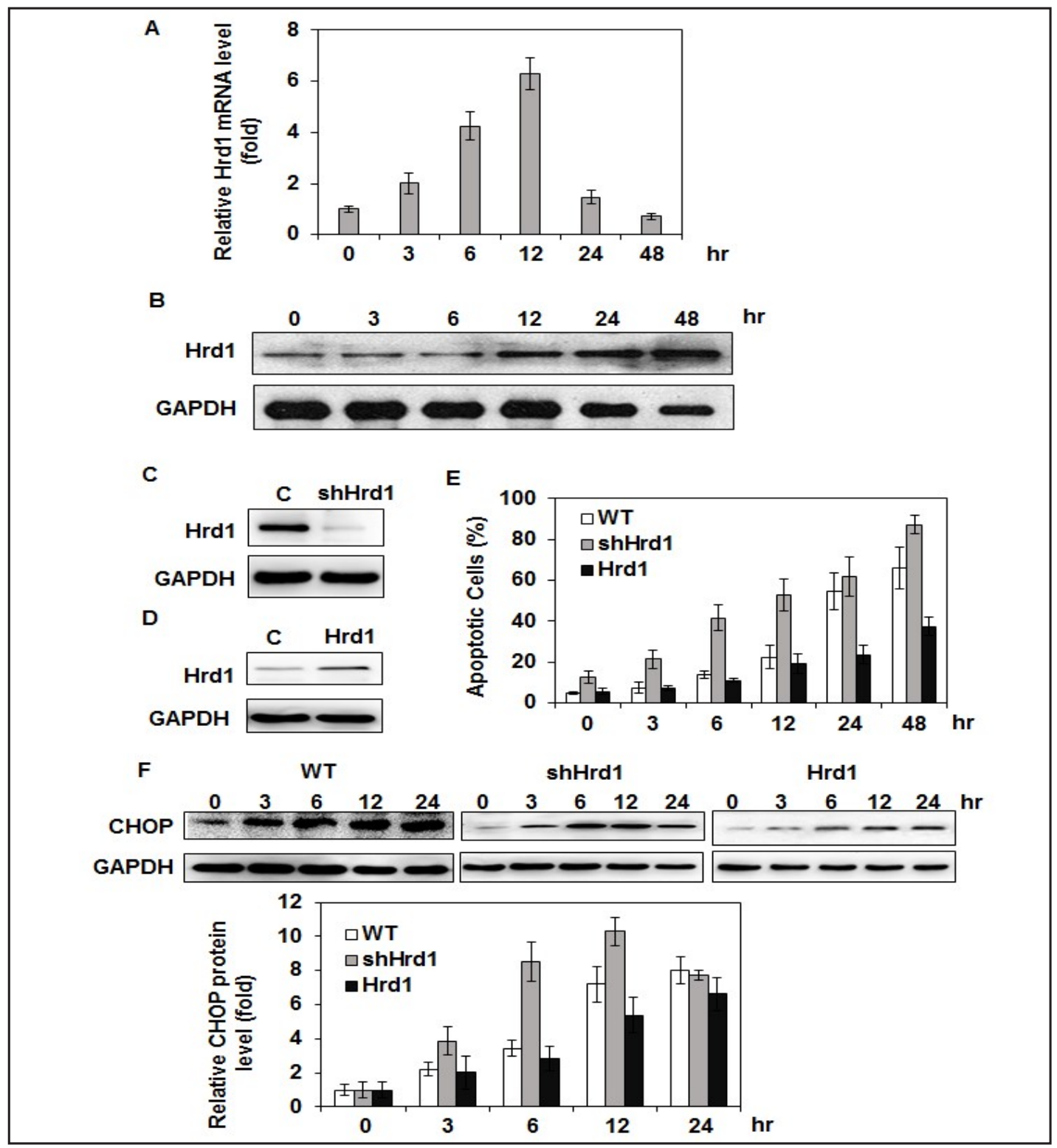

Fig. 3. ER stress induces Hrd1 which then protects ACEII from CSE induced apoptosis. A. Hrd1 mRNA was induced by CSE. Total RNA was prepared from ACEII treated with 10\% CSE for indicated time. qPCR was used to detect Hrd1 mRNA level, $\beta$-actin mRNA was internal control. B. Hrd1 protein was induced by CSE. Total protein lysate was prepared from ACEII treated with $10 \%$ CSE for indicated time. Western blot analysis was performed to detect Hrd1 protein. GAPDH was loading control. C. Representative blots to show lentiviral mediated knockdown of Hrd1 in ACEII. GAPDH was loading control. C: Control cells. D. Representative blots to show overexpression of Hrd1 in ACEII. GAPDH was loading control. C: Control cells. E. ACEII wild type, shHrd1 knockdown, Hrd1 overexpression cells were cultured in 6-well plates and then treated with $10 \%$ CSE for indicated time. Apoptosis of cells was determined by flow cytometry. F. ACEII wild type, shHrd1 knockdown, Hrd1 overexpression cells were treated with 10\% CSE for indicated time. Total cell lysate was prepared and Western blot analysis was performed to detect CHOP protein. GAPDH was loading control. Relative CHOP protein level was determined by densitometry analysis $(n=3)$.

not significant (Fig. 3F). Collectively, these results suggest that Hrd1 protects cells from CSE induced apoptosis, possibly through the alleviation of UPR. 


\section{Discussion}

AECII alveolar epithelial cells are responsible for oxygen and carbon dioxide exchange with external environment. AECII can decrease surface tension to prevent atelectasis and absorb fluid to prevent pulmonary edema. AECII help maintain normal air exchange function of the lung, and possess stem cell function in lung development and damage repair $[5,6]$. Because the biological characters of AECII are highly dependent on lung microenvironment, AECII would lose specific characteristics and differentiate into AECI after in vitro culture [22]. Therefore, in this study, we systematically improved the preparation and culture condition to maintain AECII morphology. Using our culture and passage methods, AECII can maintain typical morphology and characteristics after 3 passages, providing a nice model for further studies.

Recently, apoptosis of lung structural cells was considered as a major pathogenesis factor for COPD. Our results found that exposure of primary AECII to CSE activated ER stress and led to ER stress induced apoptosis in a dose and time dependent manner. After CSE treatment, we observed the activation of ER stress specific pro-apoptotic signaling pathway, such as increased levels of ER specific caspase 12, phosphorylated JNK, and CHOP. These results demonstrated that CSE treatment induces apoptosis through ER stress in AECII and CSE induced apoptosis of AECII may play an important role in COPD pathogenesis.

ER is very important to maintain homeostasis in the cells. Any perturbation of ER function would lead to the accumulation of unfolded/misfolded proteins in ER lumen. Our results showed that CSE exposure activated ER stress sensors PERK and IRE1. Activation of ER stress signaling pathway would not only signal AECII to apoptosis, but also initiate protective mechanism to counteract CSE induced UPR to protect AECII. We also observed that CSE induced the upregulation of Hrd1, which functions as an E3 ligase to specifically target the degradation of unfolded/misfolded proteins through ERAD. Knockdown of Hrd1 in ACEII sensitized AECII to CSE induced apoptosis, while overexpression of Hrd1 enhanced the resistance to CSE induced apoptosis, suggesting that Hrd1 could protect ACEII from CSE induced ER stress through the enhancement of ERAD.

\section{Acknowledgements}

This study was supported by grant from Natural Science Foundation of China (No. 81070035).

\section{Disclosure Statement}

No.

\section{References}

1 Wang J, Bao L, Yu B, Liu Z, Han W, Deng C, Guo C: Interleukin-1 $\beta$ Promotes Epithelial-Derived Alveolar Elastogenesis via $\alpha v \beta 6$ Integrin-Dependent TGF- $\beta$ Activation. Cell Physiol Biochem 2015;36:2198-2216.

2 Denic V, Quan EM, Weissman JS: A luminal surveillance complex that selects misfolded glycoproteins for ER-associated degradation. Cell 2006;126:349-359.

- 3 Yamada Y, Tomaru U, Ishizu A, Ito T, Kiuchi T, Ono A, Miyajima S, Nagai K, Higashi T, Matsuno Y, Dosaka-Akita H, Nishimura M, Miwa S, Kasahara M: Decreased proteasomal function accelerates cigarette smoke-induced pulmonary emphysema in mice. Lab Invest 2015;95:625-634.

4 Bodas M, Min T, Vij N: Lactosylceramide-accumulation in lipid-rafts mediate aberrant-autophagy, inflammation and apoptosis in cigarette smoke induced emphysema. Apoptosis 2015;20:725-739. 


\section{Cellular Physiology Cell Physiol Biochem 2017;43:1337-1345 \begin{tabular}{ll|l} 
and Biochemistry 10.1159/000481845 & $\begin{array}{l}\text { O 2017 The Author(s). Published by S. Karger AG, Basel } \\
\text { www.karger.com/cpb }\end{array}$
\end{tabular} \\ Tan et al.: HRD1 Protects AECII from Apoptosis}

5 Xu W, Xu B, Zhao Y, Yang N, Liu C, Wen G, Zhang B: Wnt5a reverses the inhibitory effect of hyperoxia on transdifferentiation of alveolar epithelial type II cells to type I cells. J Physiol Biochem 2015;71:823-838.

-6 Lopez B, Maisonet TM, Londhe VA: Alveolar NF- $\kappa B$ signaling regulates endotoxin-induced lung inflammation. Exp Lung Res 2015;41:103-114.

7 Lee KY, Park SY, Park S, Hong GH, Moon KA, Kim YS, Oh YM, Kwon HS, Kim TB, Moon HB, Cho YS: Progranulin protects lung epithelial cells from cigarette smoking-induced apoptosis. Respirology 2017;22:1140-1148.

-8 Hosokawa N, Kamiya Y, Kamiya D, Kato K, Nagata K: Human OS-9, a lectin required for glycoprotein endoplasmic reticulum-associated degradation, recognizes mannose-trimmed N-glycans, J Biol Chem 2009;284:17061-17068.

-9 Gan G, Hu R, Dai A, Tan S, Ouyang Q Fu D, Jiang D: The role of endoplasmic reticulum stress in emphysema results from cigarette smoke exposure. Cell Physiol Biochem 2011;28:725-732.

-10 Fan T, Chen L, Huang Z, Wang W, Zhang B, Xu Y, Mao Z, Hu H, Geng Q: Autophagy Activation by Rapamycin Before Hypoxia-Reoxygenation Reduces Endoplasmic Reticulum Stress in Alveolar Epithelial Cells. Cell Physiol Biochem 2017;41:79-90.

11 Nemmar A, Al-Salam S, Yuvaraju P, Beegam S, Yasin J, Ali BH: Chronic Exposure to Water-Pipe Smoke Induces Alveolar Enlargement, DNA Damage and Impairment of Lung Function. Cell Physiol Biochem 2016;38:982-992.

12 Li S, Guo L, Qian P, Zhao Y, Liu A, Ji F, Chen L, Wu X, Qian G: Lipopolysaccharide Induces Autophagic Cell Death through the PERK-Dependent Branch of the Unfolded Protein Response in Human Alveolar Epithelial A549 Cells. Cell Physiol Biochem 2015;36:2403-2417.

-13 Hoseki J, Ushioda R, Nagata K: Mechanism and components of endoplasmic reticulum-associated degradation. J Biochem 2010;147:19-25.

14 Hosokawa N, Wada I, Nagasawa K, Moriyama T, Okawa K, Nagata K: Human XTP3-B forms an endoplasmic reticulum quality control scaffold with the HRD1-SEL1L ubiquitin ligase complex and BiP. J Biol Chem 2008;283:20914-20924.

15 Ballweg K, Mutze K, Königshoff M, Eickelberg O, Meiners S: Cigarette smoke extract affects mitochondrial function in alveolar epithelial cells. Am J Physiol Lung Cell Mol Physiol 2014;307:L895-L907.

16 Vashist S, Ng DT: Misfolded proteins are sorted by a sequential checkpoint mechanism of ER quality control. J Cell Biol 2004;165:41-52.

17 Meusser B, Hirsch C, Jarosch E, Sommer T: ERAD: the long road to destruction, Nat Cell Biol 2005;7:766772 .

18 Lord JM, Roberts LM, Stirling CJ: Quality control: another player joins the ERAD cast. Curr Biol 2005;15:R963-964.

19 Bernasconi R, Galli C, Calanca V, Nakajima T, Molinari M: Stringent requirement for HRD1, SEL1L, and OS-9/ XTP3-B for disposal of ERAD-LS substrates. J Cell Biol 2010;188:223-235.

-20 Kaneko M, Ishiguro M, Niinuma Y, Uesugi M, Nomura Y: Human HRD1 protects against ER stress-induced apoptosis through ER-associated degradatio. FEBS Lett 2002;532:147-152.

-21 Sano R, Reed JC: ER stress-induced cell death mechanisms. Biochim Biophys Acta 2013;1833:3460-3470.

-22 Groisman B, Shenkman M, Ron E, Lederkremer GZ: Mannose trimming is required for delivery of a glycoprotein from EDEM1 to XTP3-B and to late endoplasmic reticulum-associated degradation steps. J Biol Chem 2011;286:1292-1300. 